\title{
Two-dimensional hydrodynamic modeling of residential areas flooding using a highly detailed computational mesh
}

\author{
Alexey Sazonov ${ }^{1,2,3^{*}}$, Inna Krylenko ${ }^{1,2,3}$, Alexey Rumyantcev ${ }^{2}$, Vitaly Belikov ${ }^{1,2,3}$, and \\ Natalia Semenova ${ }^{1}$ \\ ${ }^{1}$ Lomonosov Moscow State University, Leninskie Gory GSP-1, 119991, Moscow, Russia \\ ${ }^{2}$ Water Problems Institute of the RAS, 3 Gubkin Street, 119333, Moscow, Russia \\ ${ }^{3}$ Saint Petersburg Institute for Informatics and Automation of RAS, 14-th Linia, VI, No. \\ 39,199178,St. Petersburg, Russia
}

\begin{abstract}
Modeling of 2016 year flood, the largest flood of the 21st century for the chosen area, was carried out using two-dimensional hydrodynamic model STREAM_2D on the example of Velikiy Ustyug city, located at the confluence of the Sukhona and Yug Rivers. A highly detailed computational grid created in the AutoMesh-2D editor was used for simulations. Specific feature of the created mesh is consideration of shape and relative position of buildings exposed to flooding.
\end{abstract}

\section{Introduction}

According to the Ministry of the Russian Federation for Civil Defense, Emergencies and Disaster Management, floods are one of the most common natural disasters, both in terms of impact area and frequency of occurrence, and in terms of amount of damage caused.

The break-up of northern rivers of the European territory of Russia (ETR) is often accompanied by ice jams. The Northern Dvina, Pechora and Onega Rivers - the large rivers of this region - flow from south to north, and, therefore, their break-up begins from the upper reaches. The Northern Dvina River basin is one of the most affected by flooding areas in the northern part of the ETR, where ice jams regularly form, leading to a $9 \mathrm{~m}$. or more rise of the water level.

Traditionally, modeling of floods in urban areas is carried out by identifying individual areas, where an increased roughness coefficient, usually taken equal to 0.1 , is established. Linear objects, such as flood dam sand road embankments, are taken into account in models as separate areas with fixed values of elevation and the corresponding roughness coefficient. Although this approach is widely used in applied hydrology, it has a number of drawbacks, one of which is the assumption of surface homogeneity and, hereupon, use of the interpolation method. At the same time, while modelling floods in urban areas, the flow resistance of individual buildings, which depends on their shape and size, is practically not taken into account.

${ }^{*}$ Corresponding author: sazonov.lesha@gmail.com 
In Russia, the use of detailed computational meshes for flood modeling in urban areas is currently not widespread, although the Water Problems Institute of the Russian Academy of Sciences has experience of similar flood modeling for Yaroslavl and Krymsk cities [1]. By the example of the city of Velikiy Ustyug, an attempt to adapt the two-dimensional hydrodynamic model STREAM_2D for the city was made, taking into account all residential and utility buildings, as well as to calculate the flood of ice-jam genesis. Such modeling became possible with the growth of computing power (in this case, the station for engineering modeling was used).

This article proposes a new approach to floods modeling of urbanized territories in domestic practice. The main idea of the current stage of research is the creation of a highly detailed computational grid for a two-dimensional hydrodynamic model, where each city structure would be removed from the computational area. This approach allows to increase the modeling accuracy for the flood characteristics due to the fact that in the area of buildings there is no interpolation of values, that is, buildings located on the simulated area are presented in the form of infinitely high structures. On the street areas, that is, in the sections between the "cut out" houses, the dynamics of the water flow, the flow velocity and the influence of backwater supposed to be simulated with great accuracy.

\section{Materials and methods}

\subsection{Description of the STREAM_2D two-dimensional hydrodynamic model}

The STREAM_2D Russian model [2], based on the solution of Saint-Venant system of equations, was used to calculate the flood characteristics in this work. This system of equations, known as shallow water equations, is a system of hyperbolic partial differential equations and describes flows under the surface of a liquid. The initial bottom surface and the corresponding instantaneous velocity and depth fields are taken as the initial conditions for modeling. Water and sediment discharges and / or water surface levels are specified for the liquid boundaries.

The relatively small section of less than $10 \mathrm{~km}$ length, where the city of Velikiy Ustyug is located, was chosen within the framework of already existing hydrodynamic model of the territory about $69.5 \mathrm{~km}$ length, from the confluence of the Sukhona and Yug Rivers to the city of Kotlas.

\subsection{Initial data for constructing a detailed grid on the territory of the city of Velikiy Ustyug}

Open Street Map data was used as initial information on housing premises and utility structures located within the Velikiy Ustyug city limits. 3276 residential and utility buildings for various purposes are located within the city territory according to the sample made by the QGIS 3.10 program.

Preparatory work consisted of three stages was carried out in the QGIS 3.10 program to create a computational grid:

1. Visual control was made for all polygons, displaying buildings. Manual correction of problem areas was carried out for the cases of detection of nested polygons or intersections at a single point in the contours of buildings. The formation of an acute angle, which makes impossible to construct a grid inside the angle area, is the reason for performing of such an editing; 
2. A square grid with cell size $250 \times 250 \mathrm{~m}$. was placed on the territory of the city at the second stage. This operation is necessary to divide a large data array into separate sectors with the possibility of separate processing for each of them.

3. At the final stage of data preparation, the entire group of objects (polygonal buildings and a linear grid superimposed on the city) was converted from the SHP format used in GIS packages to the DXF format used in AutoCAD and in the AutoMesh-2D grid builder program.

\subsection{Grid modeling in AutoMesh-2D program}

AutoMesh-2D meshing software was developed at Jinan University (China). Initially, this program was written to build a mesh that is used in the molding of metal parts [3].

The process of constructing of a computational grid in the AutoMesh-2D program consists of five stages:

1. The division of the construction area into separate sections, limited by direct lines. At this particular stage the area under consideration is divided into two classes: "houses" and "flood area".

2. At the second stage the lines are divided into intervals. In the AutoMesh-2D program user is prompted to select the method of splitting - by the length of a given segment or by the number of intervals. In the research the partition was made by the 10 -meter-long segment. If the building was less than 10 meters long, the program set a point at the ends of the segment.

3. At the third stage the actual meshing was performed. AutoMesh-2D program allows building grids using various algorithms, both rectangular and triangular. An irregular rectangular grid was used for the urban area, which adapts well to the outlines of streets and buildings. The algorithm used to construct the grid was described by South Korean scientists in [4].

4. Manual correction of problem areas was performed after the grid plotting. The AutoMesh-2D program allows you to automatically detect the incorrectly constructed mesh cells according to one of seventeen criteria: by the maximum angle between the grid lines, the minimum angle, aspect ratio of the quadrangle or triangle, distortion, shape, Jacobian, etc. In the research about 100 grid cells were manually corrected with preliminary ordering of incorrect elements by distortion and aspect ratio.

5. The final stage is the adaptation of the resulting computational mesh for the STREAM_2D hydrodynamic model.

\section{Using a highly detailed hydrodynamic model as an example for the outstanding flood of 2016}

The largest flood of the XXI century in the area of the city of Veliky Ustyug was the flood of 2016. Its cause is a set of prevailing weather conditions in the autumn-winter period of 2015-2016. [5]. From November to December the air temperature in the basin of the Northern Dvina River exceeded the long-term average value. This led to the breaking up of river ice in early December due to warm rains, with the following ice drifting, which lasted more than two weeks. These circumstances led to the formation of long ice hummock areas and the presence of a large amount of sludge under the ice.

The repeated formation of ice jams was one of the features of winter ice drift in the lower reaches of the Sukhona River in the fall of 2015. On December 23, 2015, in the city of Velikiy Ustyug area the highest water level for December for the entire observation period from 1881 to 2015 equal to $674 \mathrm{~cm}$ above the zero post was recorded. The freeze-up 
took place at high water levels, which persisted in early February and were comparable to average water levels during the spring ice drift.

On April 13, the Sukhona River opened, on April 14 an ice jam formed and a sharp increase of water level began in the Velikiy Ustyug city area. The maximum water level amounted to $960 \mathrm{~cm}$ was recorded at the gauge station of Velikiy Ustyug on April 18 [5]. Three days - April 16, 17 and 18, when the highest water levels were observed - were chosen as the time period for the flood modeling. At the time of the flood peak, on April 18, the distribution of depths and velocities within the territory under consideration was analyzed according to the results of the simulation.

The Landsat- 8 satellite image, taken at the time of the flood peak, was used to compare the boundaries of the flood obtained by the STREAM-2D modeling with the actual data. The mask of the flooded area was obtained using automatic classification according to the $\mathrm{K}$-means method in compliance with the satellite image. According to the satellite imagery the flood area was equal to $2 \mathrm{~km}^{2}$, while the simulation data gives value of $1.85 \mathrm{~km}^{2}$. Thus, the relative simulation error was $7.5 \%$, what can be considered as a good result.

The right-bank settlements in the area were flooded due to establishment of the ice jam, and in some places the width of the flood front was about $1 \mathrm{~km}$. The villages of Koromyslovo, Barsukovo, Ivashevo, Dymkovo and Dobrynino fell into the flood zone. The greatest flooding depth was noted in the vicinity of the villages of Barsukovo and Ivashevo, where it reached $5 \mathrm{~m}$. In the city of Velikiy Ustyug, relatively low central part was flooded, from Krasnaya Street, which is regularly flooded near the embankment, to Tsvetochnaya Street. In the lowest part of the city, the depth of flooding, according to the modeling data, was $1.5-2 \mathrm{~m}$. In most of the flooded area it was $0.5 \mathrm{~m}$.

The maximum flow velocity in the deep stream reaches $1 \mathrm{~m} / \mathrm{s}$, however, it dies away towards the bank and decreases practically to zero value in the urban areas. The central part of the city deserves special attention, where the shallow gully acts as a channel. Water movement is observed at this area, and the flow velocity reaches $0.4 \mathrm{~m} / \mathrm{s}$.

It should be noted that a more detailed digital relief model is needed to improve the quality of further modeling. Such a model can be obtained by survey of the flooded areas of the city using a quadrocopter.

The computational grid construction was carried out with financial support from the RSF grant No. 17-11-01254, the flood simulation was carried out with financial support from the RFBR grant 18-0560021 Arctic.

\section{References}

1. S. Norin, V. Belikov, A. Aleksyuk, Hyd. Const., 12, P. 15-21 (2016)

2. V. Belikov, V. Kochetkov, Software package STREAM_2D for calculating of flows, bottom deformations and pollution transfer in open streams // Certificate of the official registration of a computer program No. 2014612181. M., (2014)

3. X. Ma, G. Zhao, L. Sun, Mater. Res. Innov., 15, pp. 482-486(2011)

4. K.-Y. Leeetal.,Comp-AidedDes., 35, pp. 1055-1068 (2003)

5. N. Frolova, S. Agafonova, I. Krylenko, A. Sazonov, Proc. of the V All-Rus. Con., pp. 434-440 (2016)

6. M. Georgievsky, N. Goroshkova, V. Polyakova, O. Golovanov, D. Georgievsky, Met. Gid, 2, pp. 108-114 (2018) 